DOI: 10.2478/ausae-2021-0011

\title{
Preliminary results regarding the seed yield of pot marigold (Calendula officinalis L.) plants harvested at different stages of seed maturity
}

\author{
Béla BIRÓ-JANKA, ${ }^{*}$ Katalin MOLNÁR, Norbert SZÉKELY, \\ Imre-István NYÁRÁDI
}

Sapientia Hungarian University of Transylvania (Cluj-Napoca, Romania), Department of Horticulture, Faculty of Technical and Human Sciences, Târgu-Mureş

*e-mail: bela.biro@ms.sapientia.ro

Manuscript received 31 October 2021;

revised 4 November 2021; accepted 6 November 2021

\begin{abstract}
During the study, the characteristics of flower heads and seed yield of marigold (Calendula officinalis L.) plants harvested at different stages of seed maturity (achenes from different types of heads - primary, secondary, and tertiary ramifications) were measured. The number of total flower heads (inflorescences), heads with mature seeds, and the diameter of heads with mature seeds and weight of seeds of the above mentioned fractions per plant were calculated. The results show that there are significant differences among treatments regarding several parameters. The plants were harvested when $90 \%$ of the heads formed on the primary ramifications and $75 \%$ of the heads formed on the secondary ramifications, having mature seeds superior to plants with $50 \%$ of the secondary heads with mature seeds.
\end{abstract}

Keywords: growth period, number and diameter of heads, ramifications

\section{Introduction}

Pot marigold, or calendula (Calendula officinalis), from the Asteraceae family is an annual plant originating from the Mediterranean area [1]. It is cultivated around the globe, predominantly for ornamental purposes [2]. Its medicinal properties are also known, the inflorescences being used for the treatment of several diseases [3]. There is a vast literature on the composition of the flowers and their pharmaceutical properties $[4,5,6,7]$.

In recent years, calendula has been rediscovered as an industrial oil-bearing crop [8]. Its seeds (achenes) contain around 20\% of fatty acid, of which calendulic acid constitutes approximately 60\% [9]. This component has a special chemical 
structure [10], which provides such properties that make it suitable for utilizations such as coatings, paints, cosmetics [1], adhesives, and replacement for volatile organic compounds (VOCs) [9].

There are studies analysing the effects of plant density, applied herbicides [1], genotype [8], sowing date [9], mineral fertilizers [11], or harvest date [12] on seed yield.

As the plant develops an indeterminate number of flower heads [12], defining the proper harvest time could be difficult since the maturing of seeds is continuous on the one hand, but previously ripened seeds tend to fall off the plant on the other hand.

Another problem originates from the fact that flower heads developed on different ramifications of the plant reach maturity at various rates, this also contributing to the uncertainty of optimal harvest time.

The purpose of this pilot experiment was data acquisition for the determination of the best phenological phase of the plant for achieving the highest seed yield under the climatic conditions of the area.

\section{Materials and methods}

\section{Experimental site and experimental design}

The field study took place in 2020, in the Medicinal and Aromatic Plants Garden belonging to the Didactical and Research Field of the Faculty of Technical and Human Sciences, Târgu-Mureş, of Sapientia Hungarian University of Transylvania, situated in Târgu-Mureş, Mureş County, Romania. The monthly average temperature values and the sums of precipitation of 2020 compared to the multiannual values (period of 1971-2000) are presented in Table 1.

Table 1. Air temperature and precipitation values during the vegetation period of the experimental year and the multiannual mean values representative of the area

\begin{tabular}{lcccc}
\hline Year & \multicolumn{4}{c}{ Month } \\
\cline { 2 - 5 } & \multicolumn{1}{c}{ May } & June & July & August \\
\cline { 2 - 5 } Average air temperature $\left({ }^{\circ} \mathrm{C}\right)$ & & & \\
2020 & 13.0 & 18.6 & 19.8 & 20.7 \\
$1971-2000$ & 15.7 & 18.5 & 20.2 & 19.6 \\
Precipitation (mm) & & & & \\
2020 & 71 & 124 & 74.2 & N/D \\
$1971-2000$ & 65.1 & 84.8 & 76.6 & 66 \\
\hline
\end{tabular}


The three treatments (seeds' maturity duration at the time of harvesting) and four replications were scheduled in a randomized complete block design (RCBD), with each plot having a $10 \mathrm{~m}^{2}(2 \times 5 \mathrm{~m})$ area and consisting of five rows. Data collection was carried out in the three central rows from a number of 12 randomly selected plants in the case of each replication.

\section{Preparation of the experimental field}

In the autumn of 2019, a $25 \mathrm{~cm}$ deep ploughing was performed, followed by a rototilling after the pass of the cold season. Prior to sowing, the seedbeds were made manually. A total of $150 \mathrm{~kg} / \mathrm{ha}$ complex mineral fertilizer with 16:16:16 NPK content and $200 \mathrm{~kg} / \mathrm{ha}$ ammonium nitrate mineral fertilizer with $33.5 \% \mathrm{~N}$ content were applied to the field. Sowing was performed on 10 May 2020 with a $40 \mathrm{~cm}$ distance between the rows and a depth of $4 \mathrm{~cm}$. The $10 \mathrm{~cm}$ final inrow distance between plants was achieved manually after the emergence of plantlings, resulting in a plant density of 25 plants $/ \mathrm{m}^{2}$. A single dose of irrigation was applied to the field for a better and more uniform emergence of plants. The harvest was effectuated at the stages of $90 \%$ mature seeds on the primary heads and $50 \%$ and $75 \%$ mature seeds in the secondary heads of the plants (13 and 24 August and 2 September 2020). The durations of the growth periods were 96, 107, and 116 days.

\section{Data collection}

The following measurements were effectuated on the different types of heads (developed on the primary, secondary, or tertiary ramifications of the plant): number of heads and number of heads that reached seed maturity, diameter (in $\mathrm{mm}$ ) and seed yield (in g) of heads with mature seeds.

\section{Data analysis}

The data obtained were subjected to data analyses using the PAST program. In the case of data with normal distribution, ANOVA and Tukey's test were performed, while for data with non-normal distribution or represented by nominal variables, the Kruskal-Wallis and Mann-Whitney tests were used.

\section{Results and discussion}

\section{Number of flower heads per plant}

By comparing the data of total inflorescence formation on the primary ramifications among the three seed maturity groups, it can be said that there are no 
significant differences. This statement is also valid for the data of head number on secondary and tertiary ramifications and also for the total number of heads per plant regardless of the harvesting group $(\mathrm{p}>0.05)$.

In contrary, the distribution of inflorescences formed on different ramifications shows statistically significant differences in the case of plants harvested at $90 \%$ and $50 \%$ maturated seed groups, the number of heads formed on the tertiary ramifications being significantly lower than the other two head types $(\mathrm{p}<0.001)$ (Figure $1 A-B$ ). The total inflorescence number in the case of the $75 \%$ group shows no differences (Figure 1C).

Similarly to the above mentioned results, the data regarding the number of inflorescences with maturated seeds formed on primary, secondary, and tertiary ramifications and also the total number of matured inflorescences per plant presents no statistically significant differences.

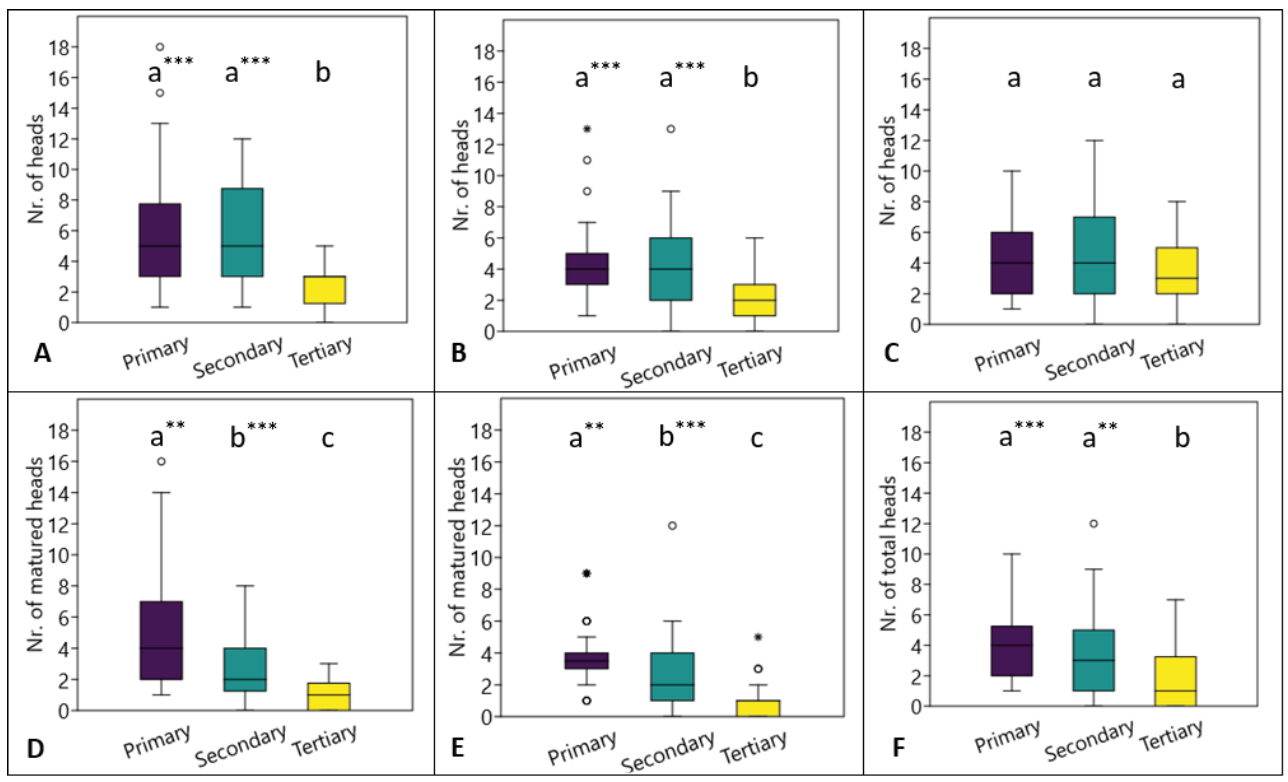

Notes: Lower case letters denote significant differences; /, //, and /// denote p values smaller than $0.5,0.01$, and 0.001 .

Figure 1. Number of total flower heads (A - 90\%, B - 50\% and C - 75\% maturity), and matured flower heads (D-90\%, E - 50\%, and F - 75\% maturity) on different ramifications

However, analysing the data obtained from plants harvested at 90\% seed maturity, we can observe a decrease in the number of heads formed on the different ramification types, the highest number of heads being formed on the primary ramifications, while 
the lowest number of heads can be observed in the case of tertiary ramifications. The same pattern is present also in the results originating from plants harvested at $50 \%$ matured seeds on secondary ramifications. The differences are statistically significant in both cases $(\mathrm{p}<0.001$ and $\mathrm{p}<0.01)$. A similar tendency is visible at the data from plants harvested at $75 \%$ maturated seeds on the secondary ramifications, but in this case only the number of heads formed on the tertiary ramifications is significantly lower than the other two types $(\mathrm{p}<0.01)($ Figure $1 D-F)$.

\section{Diameter of flower heads}

The diameter of flower heads formed on primary ramifications is greater than those from secondary and tertiary ramifications. Comparing the head diameters of different ramifications of plants from the three separate harvest times, it can be stated that the differences are statistically significant in the case of primary flower heads, the plants with $90 \%$ and $50 \%$ matured seeds having significantly higher head diameters compared to plants of $75 \%$ matured seeds (Figure 2a.A). Contrary to this, in the case of tertiary flower head diameter, the highest values come from plants of the third harvest date, followed by plants of the second and finally by the first harvest date, the differences between the first and latter two groups being significant (Figure 2a.B). This could be partially explained by the fact that the flower heads developed earlier on the primary ramifications have shrunken after ripening. There are no significant differences among the secondary flower head diameters of the plants of different harvest times. The average flower head diameter is significantly higher in the case of plants harvested at $90 \%$ and $50 \%$ seed maturity as compared to plants of $75 \%$ seed maturity (Figure 2a.C).

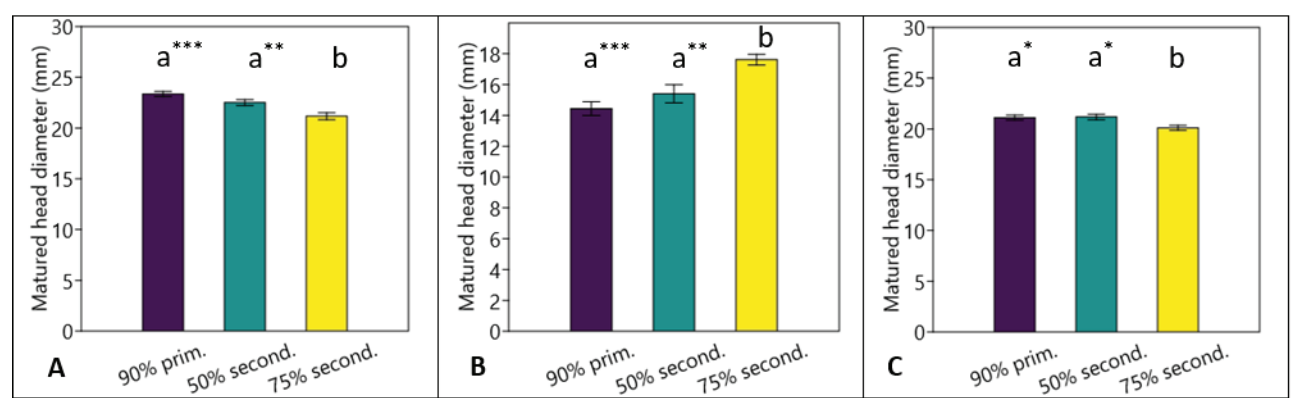

Figure 2a. Diameter of matured flower heads (A - primary, B - tertiary, and $\mathrm{C}$ - plant average) and their distribution among different ramifications in the case of the three harvest times (D - 90\%, E - 50\%, and F - 75\%) 


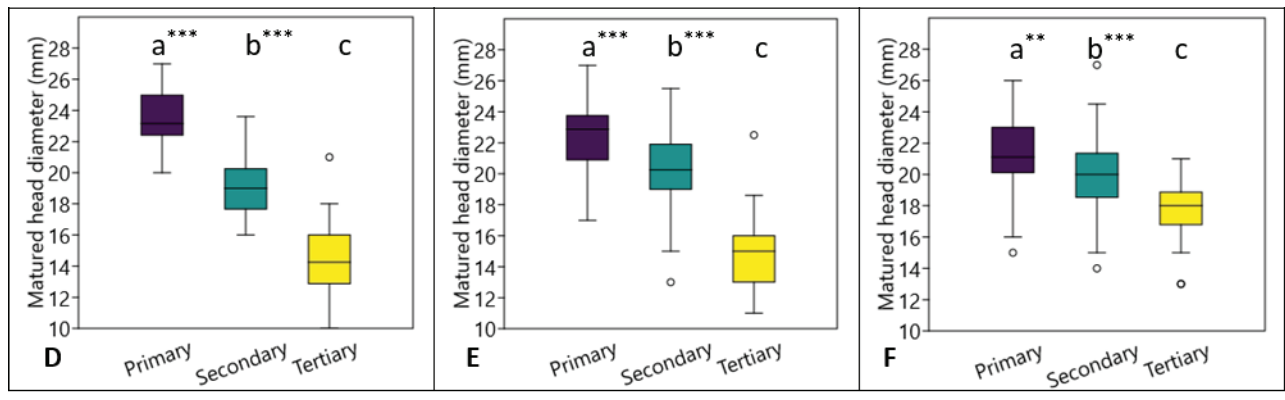

Notes: Lower case letters denote significant differences; /, //, and /// denote p values smaller than $0.5,0.01$, and 0.001 .

Figure 2b. Matured flower heads distribution among different ramifications in the case of the three harvest times (D - 90\%, E - 50\%, and F - 75\%)

The dispersion of flower heads formed on primary, secondary, or tertiary ramifications is similar for plants of all harvest dates in such a manner that the diameters' value decreases from primary to tertiary ramifications, the differences being statistically significant in all cases, with $\mathrm{p}<0.01$ or even 0.001 (Figure $2 b . D-F$ ).

\section{Weight of flower heads}

The average weight of a flower head ranges from $0.38 \mathrm{~g}$ to $2.66 \mathrm{~g}$. After analysing the data of the dispersion of flower head weights of different ramifications, we can conclude that plants harvested at $90 \%$ seed maturity have developed the flower heads with the greatest weight, followed by plants harvested at $75 \%$ and lastly plants harvested at $50 \%$ seed maturity; the differences between the first group and the latter two are statistically significant $(\mathrm{p}<0.05)$ (Figure $3 A$ ). Comparing the weights of flower heads formed on the secondary ramifications of plants harvested at different seed maturity stages, we can conclude that the lowest values come from the $90 \%$ seed maturity harvest time, followed by the $50 \%$ and $75 \%$ seed maturity groups, but without significant differences among the groups. The weight of flower heads formed on tertiary ramifications of the first two harvest times are the same, and the values of the third harvest date are significantly higher $(\mathrm{p}<0.01)$ (Figure $3 B$ ). An explanation to this phenomenon could be that plants of the third harvest date had a longer period to develop their flower heads on the tertiary ramifications.

Average per plant flower head weight was the highest in the case of plants harvested at $90 \%$ seed maturity, followed by the group of plants harvested at $75 \%$ and finally at $50 \%$ seed maturity, the differences being significant among the two extreme cases $(\mathrm{p}<0.001)$ (Figure $3 C)$. This tendency is probably due to the fact that in later harvest times part of the seeds from the primary heads have already fallen to the ground on the one hand and that flower heads of secondary and tertiary 
ramifications had a longer period to develop in the case of the third harvest date on the other hand; thus, an intermediate harvest time seems less appropriate.

Independently of the harvest date, all plants had heavier flower heads developed on the primary ramifications, followed by secondary and, finally, tertiary ramifications; however, differences are greater in the first harvest group and gradually decrease in the second and third harvest groups. It is probable that with longer growth periods, plants had the chance to develop bigger and heavier flower heads also on the secondary and tertiary ramifications. In the first and second harvest dates, there are significant differences among the values of all types of flower heads ( $p<0.001$ and $\mathrm{p}<0.01$ ) (Figure 3D-E), but in the case of the third harvest date, the weights of primary and secondary ramification flower heads do not differ significantly from each other, only from the flower heads formed on the tertiary ramifications $(\mathrm{p}<0.01)$ (Figure $3 F)$.

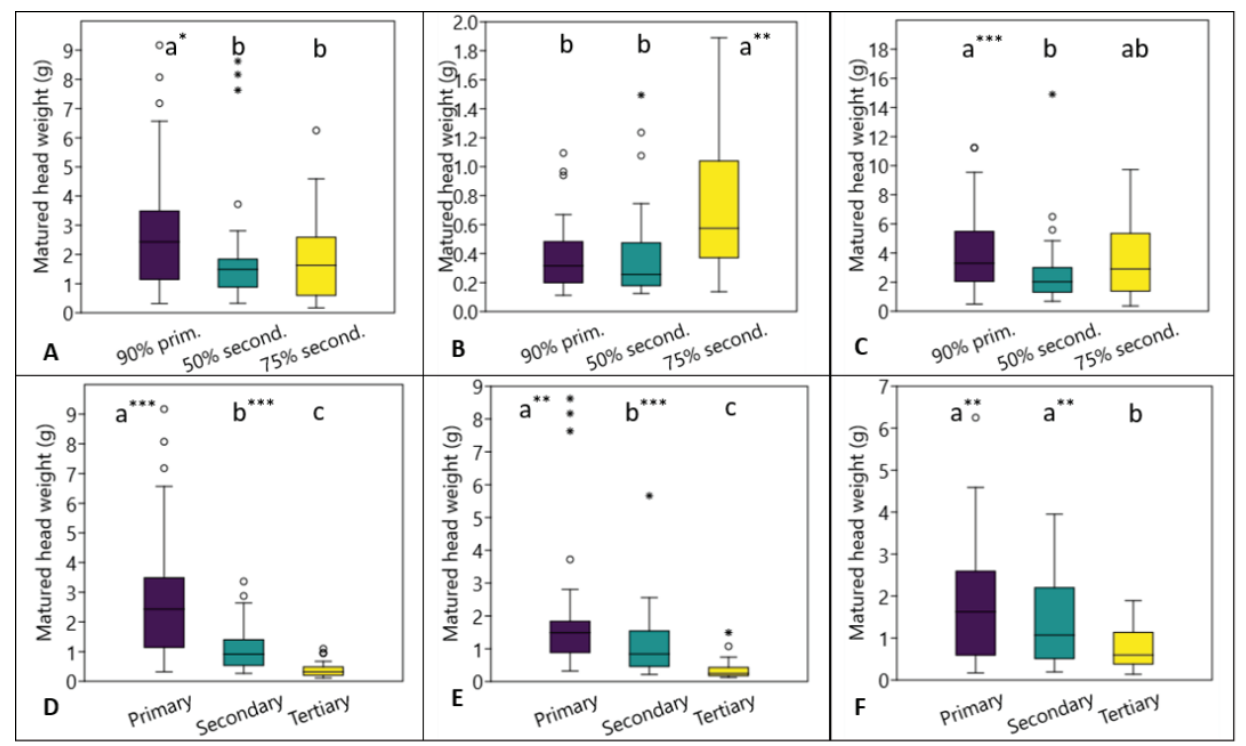

Notes: Lower case letters denote significant differences; /, //, and /// denote p values smaller than $0.5,0.01$, and 0.001 .

Figure 3. Average weight of matured flower head (A - primary, B - tertiary, and $\mathrm{C}$ - plant average) and their distribution among different ramifications in the case of the three harvest times (D - 90\%, E - 50\%, and F - 75\%)

Seed yield per hectare was calculated from the average seed yield of one plant and the plant density applied in the experiment. The results show that the highest yields were achieved when plants were harvested at $90 \%$ seed maturity on the primary ramification $(1,004.9 \mathrm{~kg} / \mathrm{ha})$, followed by plants harvested at the stage 
when $75 \%$ of heads of secondary ramifications had maturated seeds $(875.7 \mathrm{~kg} /$ ha) and, finally, by plants at a 50\% seed maturity of secondary ramification flower heads (752.8 kg/ha). These results are lower than those of [1] and [13] but are comparable to those achieved by [12].

The values of Spearman's rank correlation coefficient rho indicate that there are differences between the three harvest times regarding the positive correlation among total flower head number and the flower head count of primary, secondary, and tertiary ramifications. In the case of plants harvested at the latest date, the flower heads of tertiary ramifications contributed to a greater extent to total flower number (Table 4), while contrary, in the case of plants harvested in the first date, their contribution was of a lesser significance (Table 2). This tendency is also visible when analysing the magnitude of correlation in the case of matured head numbers.

Although there were no statistically significant differences detected between either the total or the maturated flower head numbers, there is a tendency of negative correlation (with rho values exceeding -0.5 only in one case) among flower head numbers and their diameter. In the case of plants from the first harvest group (with the shortest growth period), this effect is mostly notable at the diameter of flower heads developed on tertiary ramifications (Table 2). This trend is repeated also in the case of plants from the third harvest group (with the longest growth period), but to a lesser extent (Table 4).

For the second harvest group, the negative correlations are visible almost entirely in the cases of primary and total flower head diameters (Table 3).

A trend of positive correlation is also present between the total flower head weight of plants and the flower head weight of different ramifications. For plants harvested at $90 \%$ seed maturity, the highest contribution to the total seed yield of plants can be attributed to flower heads developed at primary ramifications (rho $=0.932$ ) followed by secondary ramification heads (rho $=0.701)$. In this case, tertiary flower head weight has a low positive correlation $(r h o=0.349)$ with total seed yield (Table 2). The data coming from the second harvest group indicates a lower correlation ratio between the mentioned parameters, with only the weight of primary ramification flower heads having a relatively high rho value of 0.722 (Table 3). Finally, concerning the plants of the third harvest group, it can be said that all types of flower heads contributed in a somewhat similar extent to the total seed yield of plants, the Spearman's rank correlations having rho values of 0.881 , 0.838 , and 0.752 (Table 4). 


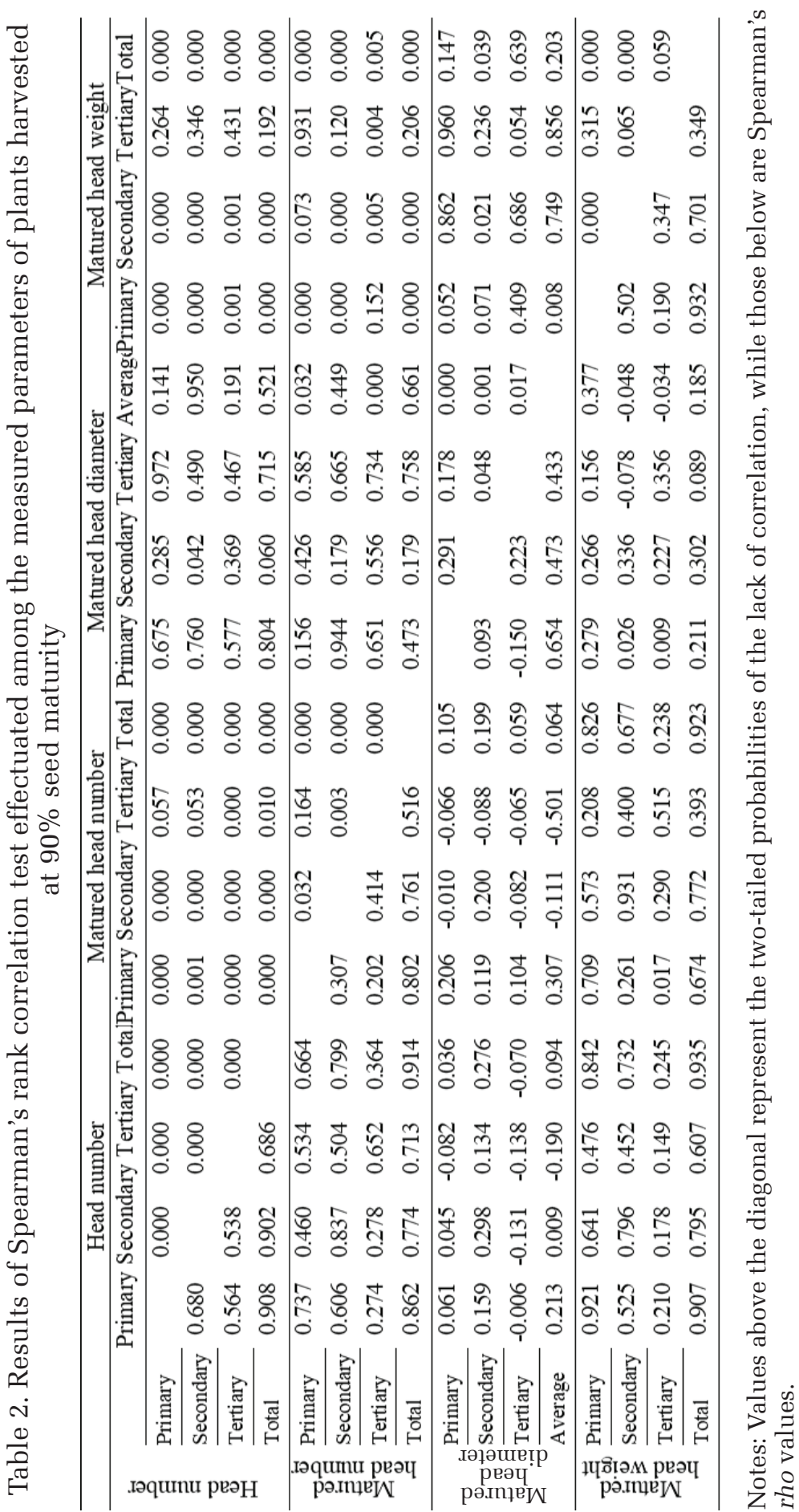




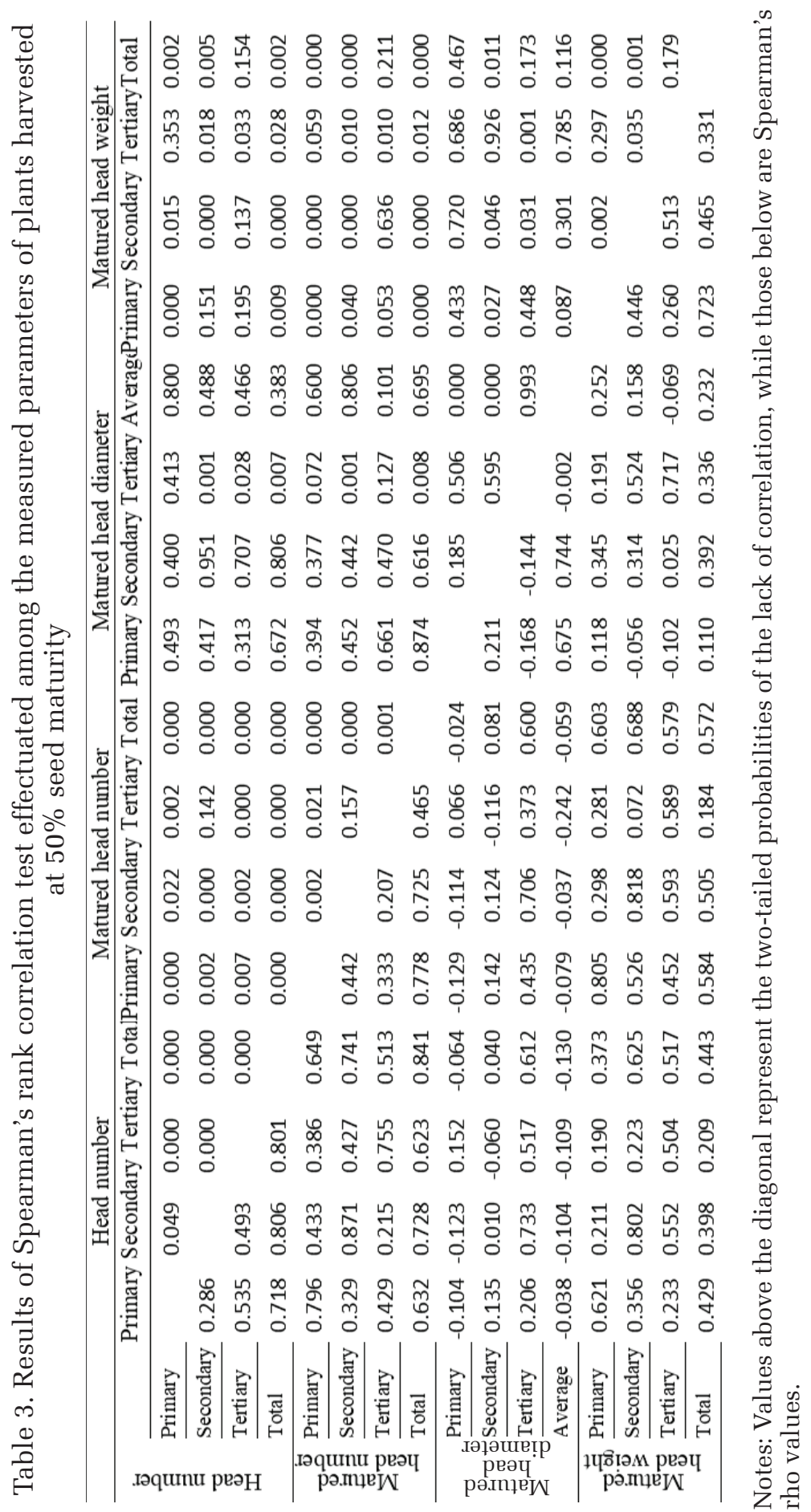




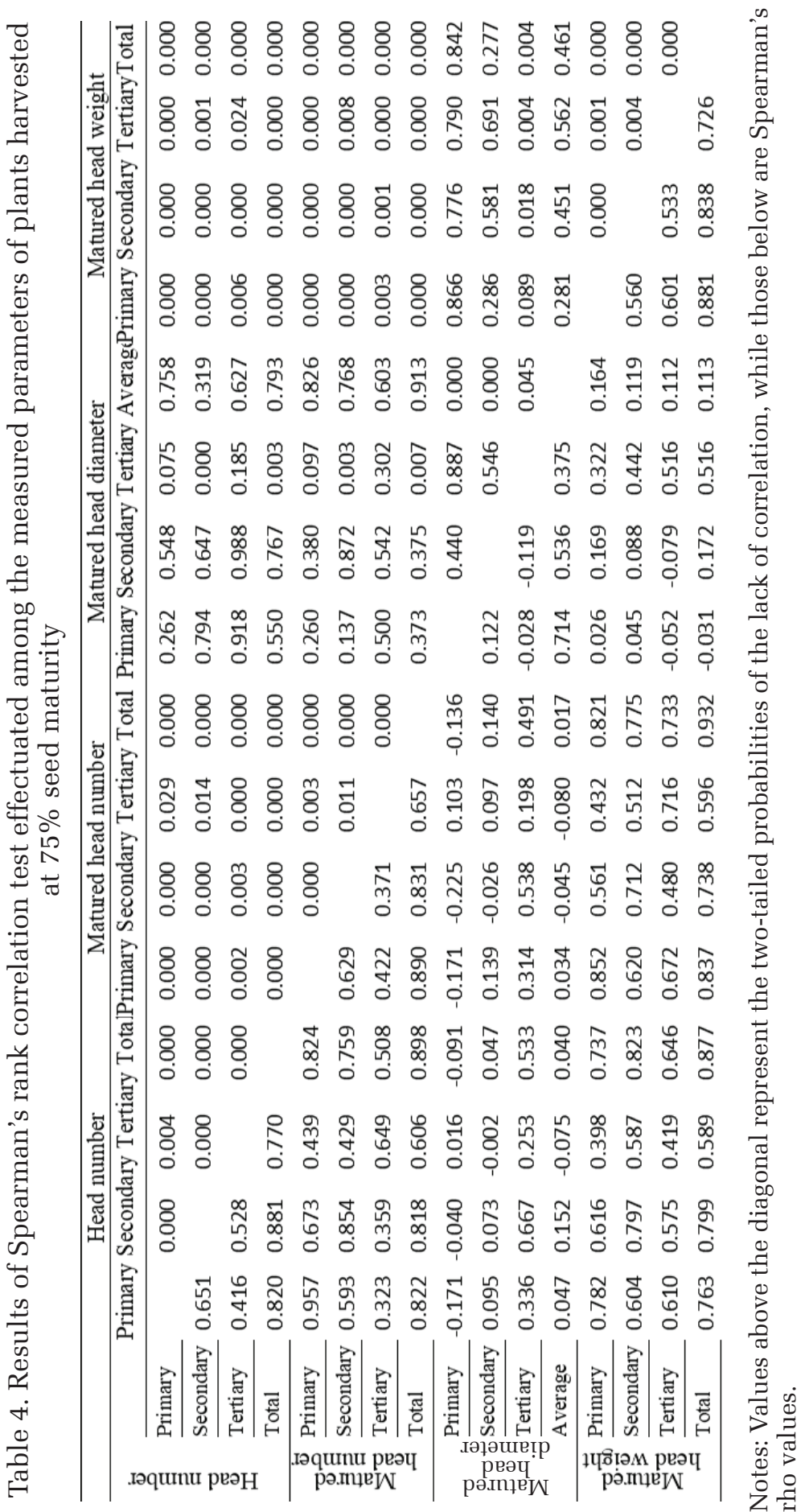




\section{Conclusions}

On the basis of the data obtained from the experiment, it can be concluded that harvest time, which determines the length of the growth period, has great influence on the flower head parameters and seed yield of Calendula officinalis plants. Results show that effectuating the harvest when the majority of primary flower heads have ripened seeds produced the highest yields, while in the intermediate harvest time plants obtained the lowest yields. An even longer growth period permits the plants to develop enough seeds on secondary and tertiary flower heads for a greater yield. A possible explanation to this phenomenon could be that after having reached full maturity, seeds on primary flower heads tend to fall off, and so they will not be present in the harvested seeds, reducing the seed yield. At the same time, a number of seeds developed on secondary and tertiary ramifications can reach maturity, thus contributing to the total seed yield. The authors' opinion is that further investigation is needed for the elucidation of further factors influencing seed yield and for determining even more accurately the proper harvest date for calendula plants.

\section{Acknowledgements}

Publishing of this journal is supported by the Institute for Research Programmes of Sapientia Hungarian University of Transylvania.

\section{References}

[1] Cromack, H. T., Smith, J. (1998), Calendula officinalis—production potential and crop agronomy in southern England. Industrial Crops and Products 7(2-3), 223-229. DOI: 10.1016/s0926-6690(97)00052-6.

[2] Eberle, C. A., Forcella, F., Gesch, R., Peterson, D., Eklund, J. (2014), Seed germination of calendula in response to temperature. Industrial Crops and Products 52, 199-204. DOI: 10.1016/j.indcrop.2013.10.031.

[3] Zaki, A. A., Qiu, L. (2019), Machaerinic acid 3-O- $\beta$-D-glucuronopyranoside from Calendula officinalis. Natural Product Research 34(20), 2938-2944. DOI: $10.1080 / 14786419.2019 .1599888$.

[4] Arora, D., Rani, A., Sharma, A. (2013), A review on phytochemistry and ethnopharmacological aspects of genus Calendula. Pharmacogn. Rev. 7(14), 179-187. DOI: 10.4103/0973-7847.120520.

[5] Muley, B. P., Khadabadi, S. S., Banarase, N. B. (2009), Phytochemical constituents and pharmacological activities of Calendula officinalis Linn (Asteraceae), Trop. J. Pharm. Res. 8(5), 455-465. 
[6] Kodiyan, J., Amber, K. T. (2015), A review of the use of topical Calendula in the prevention and treatment of radiotherapy-induced skin reactions. Antioxidants 4(2), 293-303. https://doi.org/10.3390/antiox4020293.

[7] Lim, T. K. (2013), Calendula officinalis. Edible medicinal and non-medicinal plants. Dordrecht: Springer. 213-244. DOI: 10.1007/978-94-007-7395-0_15.

[8] Angelini, L. G., Moscheni, E., Colonna, G., Belloni, P., Bonari, E. (1997), Variation in agronomic characteristics and seed oil composition of new oilseed crops in central Italy. Industrial Crops and Products 6(3-4): 313-323. DOI: 10.1016/s0926-6690(97)00022-8.

[9] Gesch, R. W. (2013), Growth and yield response of calendula (Calendula officinalis) to sowing date in the northern U.S. Industrial Crops and Products 45, 248-252. DOI: 10.1016/j.indcrop.2012.11.04.

[10] Dulf, V. F., Pamfil, D., Baciu, A. D., Pintea, A. (2013), Fatty acid composition of lipids in pot marigold (Calendula officinalis L.) seed genotypes. Chemistry Central Journal 7(1), 8.

[11] Jevdovic, R., Todorovic, G., Kostic, M., Protic, R., Lekic, S., Zivanovc, T., Secanski, M. (2013), The effects of location and the application of different mineral fertilizers on seed yield and quality of pot marigold (Calendula officinalis L.). Turk. J. F. Crop. 18, 1-7.

[12] Król, B., Paszko, T. (2017), Harvest date as a factor affecting crop yield, oil content and fatty acid composition of the seeds of calendula (Calendula officinalis L.) cultivars. Industrial crops and products 97, 242-251. DOI: 10.1016/j.indcrop.2016.12.029.

[13] Martin, R. J., Deo, B. (2000), Effect of plant population on calendula (Calendula officinalis L.) flower production. New Zealand Journal of Crop and Horticultural Science 28(1), 37-44. DOI: 10.1080/01140671.2000.9514120. 